\title{
VIBROACOUSTIC ATTENUATION EFFECT OF SANDWICH DAMPING MATERIAL ON PIPE FLOW NOISE
}

Wei-Yu Lu

Department of Systems Engineering and Naval Architecture, National Taiwan Ocean Universtiy, Keelung, Taiwan, R.O.C., luweiyu6050@yahoo.com.tw

Wei-Hui Wang

Department of Systems Engineering and Naval Architecture, National Taiwan Ocean Universtiy, Keelung, Taiwan, R.O.C.

Follow this and additional works at: https://jmstt.ntou.edu.tw/journal

Part of the Engineering Commons

\section{Recommended Citation}

Lu, Wei-Yu and Wang, Wei-Hui (2009) "VIBROACOUSTIC ATTENUATION EFFECT OF SANDWICH DAMPING MATERIAL ON PIPE FLOW NOISE," Journal of Marine Science and Technology. Vol. 17: Iss. 1, Article 6.

DOI: 10.51400/2709-6998.1975

Available at: https://jmstt.ntou.edu.tw/journal/vol17/iss1/6

This Research Article is brought to you for free and open access by Journal of Marine Science and Technology. It has been accepted for inclusion in Journal of Marine Science and Technology by an authorized editor of Journal of Marine Science and Technology. 
VIBROACOUSTIC ATTENUATION EFFECT OF SANDWICH DAMPING MATERIAL ON PIPE FLOW NOISE

Acknowledgements

Sponsorship from the National Science Council of the Republic of China for the project NSC-96-2221-E-019-055 is appreciated. 


\title{
VIBROACOUSTIC ATTENUATION EFFECT OF SANDWICH DAMPING MATERIAL ON PIPE FLOW NOISE
}

\author{
Wei-Yu Lu* and Wei-Hui Wang*
}

Key words: sandwich damping material, finite element method, boundary element method, experimental modal analysis.

\begin{abstract}
The attenuation effects of a number of sheathing materials on pipe flow noise are assessed by numerical simulations of the sound pressure field around pipe wall and the transfer mobility function of pipe wall vibration. The simulation model is established by using the finite element method (FEM) and the boundary element method (BEM), in which solid elements are used for the pipe wall and the sheathing material. Between pipe wall and sheathing material, contact elements are adopted. The frequency dependent loss factors of the sheathing material are determined by the experimental modal analysis (EMA) based on the half power method in the peak frequency bands and are expressed in terms of equivalent Rayleigh's damping form. Also, the EMA has conducted to validate the simulation model of pipe flow induced sound level and pipe wall vibration. Six types of sheathing material, i.e., (1) rock wool (2) glass wool (3) PE (polyethylene) (4) PU (polyurethane) (5) PE + lead sheet (6) glass wool + aluminum, are considered to compare their effectiveness in attenuating pipe flow noise. Both the analysis and experiment results show that the sandwich damping materials can further reduce the radiated pipe flow noise by an amount of $12 \sim 15 \mathrm{~dB}$ than that using pure sound absorptive material for pipe sheathing.
\end{abstract}

\section{INTRODUCTION}

Most existing piping systems installed in factories, ships or apartment buildings are used to convey liquid or gas in a considerable high speed for the purpose of industrial demand, machine operation or life supporting. Inevitably, this can lead to a very complicated problem of pipe flow induced noise and vibration. In which, the related issues encompassing: (1) internal pipe flow disturbance induced pipe wall vibration and external acoustic radiation [1, 8, 9]; (2) structure-borne sound transmission through pipe wall $[3,4,7]$; and (3) vibration reduction of pipe wall in piping system with disturbed internal turbulent flow $[2,5]$ etc., have investigated in the past decades.

On measuring the elastic modulus and shear modulus of the

Paper submitted 09/11/07; accepted 01/29/08. Author for correspondence: Wei-YuLu (e-mail: luweiyu6050@yahoo.com.tw).

* Department of Systems Engineering and Naval Architecture, National Taiwan Ocean Universtiy, Keelung, Taiwan, R.O.C. sandwich cylinder, Ping et al. [10] developed a method of measurement based on modal testing. In which, the axial elastic modulus are determined by solving the bending vibration equations of the pipe, once the modal testing provides the required bending frequencies in the equations. Meanwhile, the shear modules can also be determined simultaneously. In some cases, it is necessary to limit the vibrations of lightly-damped shells or pipes by applying a damping treatment that does not increase the weight, Masti and Sainsbury [6] explores an optimal design procedure on the placement of damping patches by means of the modal strain energy intensity distribution of the undamped structure.

The work of this paper is engaged in establishing a methodology for evaluating the vibroacoustic attenuation effect by using sandwich damping material on pipe flow noise. To sheathe pipe wall for attenuating noise radiation, the effectiveness of several damping materials, such as rock wool, glass wool, poly ethylene, poly urethane etc., combined with lead sheet or aluminum foil are compared. Mobility simulation of pipe wall by FEM and experimental validation have been carried out. By using the established procedure, the effectiveness of diverse sandwich sheathing materials on vibroacoustic attenuation of pipe wall can be rated.

\section{SOUND SPECTRUM MEASUREMENT OF PIPE FLOW}

One case of the pipe flow noise is generated by the gas and liquid supply piping systems installed in a factory, as show in Fig. 1. During the operation of the pumping system, huge noise is measured. Ambient noise induced by pipe flow reaches to a level of $97.1 \mathrm{~dB}(\mathrm{~A})$ and $96.5 \mathrm{~dB}(\mathrm{~A})$ adjacent to the piping system in pump room and outdoors respectively. The measured sound level pressure (SPL) spectra are shown in Figs. 2 and 3. It shows that peak frequency bands of these noise spectra are occurred at the central frequencies of $3.15 \mathrm{kHz}$ and $4 \mathrm{kHz}$.

Owing to the arrangement of this piping system having passed through a number of office spaces vertically, thus pipe wall sheathing was adopting to reduce the pipe noise radiation. Originally, the sheathing material used was glass wool together with a plastic film. This pipe sheathing has resulted in reduction of office noise by an amount of $16.9 \mathrm{~dB}(\mathrm{~A})$ as shown in Table 1 , and a reduction of $4 \mathrm{kHz}$ noise by $17 \sim 21 \mathrm{~dB}(\mathrm{~A})$, as show in 


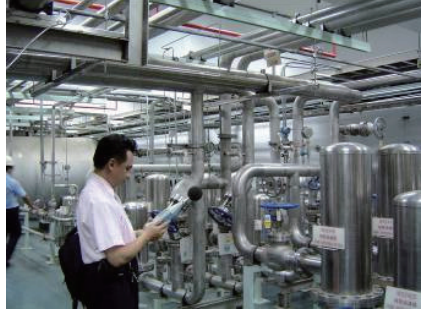

(a) Piping in pump room

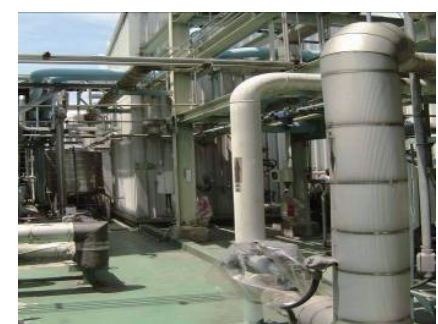

(b) Outdoor piping
Fig. 1. Piping system in a factory.

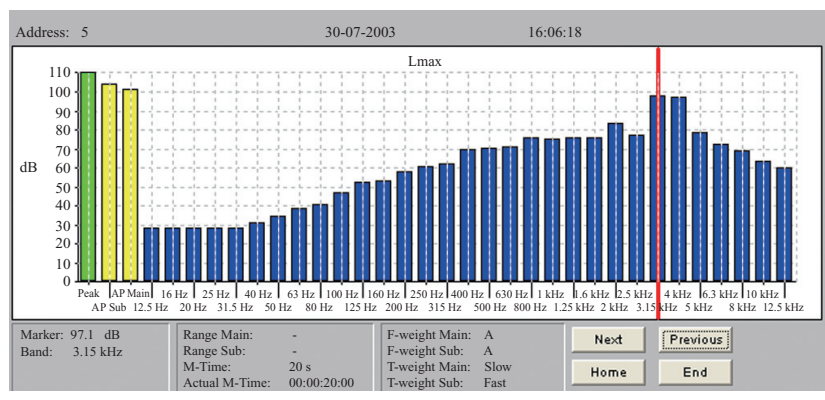

Fig. 2. SPL spectrum measured alongside piping system in pump room.

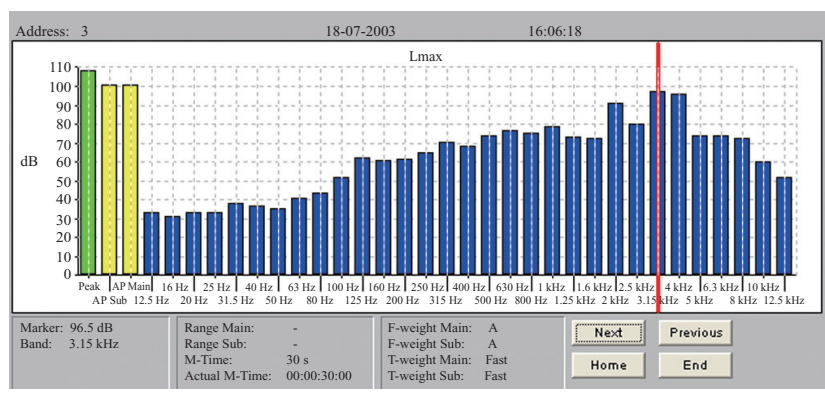

Fig. 3. SPL spectrum measured alongside piping system outdoors.

Table 1. Reduction of total noise by pipe sheathing with glass wall and plastic film.

\begin{tabular}{|c|c|c|c|}
\hline Site & $\begin{array}{c}\mathrm{L}_{\mathrm{eq}} \text { of total noise } \\
\text { before pipe } \\
\text { sheathing, } \mathrm{dB}(\mathrm{A})\end{array}$ & $\begin{array}{c}\mathrm{L}_{\mathrm{eq}} \text { of total noise } \\
\text { after pipe } \\
\text { sheathing, } \mathrm{dB}(\mathrm{A})\end{array}$ & $\begin{array}{c}\text { Total noise } \\
\text { reduction dB(A) }\end{array}$ \\
\hline Office 1 & 79.4 & 62.5 & 16.9 \\
\hline Office 2 & 95.4 & 78.5 & 16.9 \\
\hline
\end{tabular}

Table 2. Reduction of $4 \mathrm{kHz}$ noise by pipe sheathing with glass wall and plastic film.

\begin{tabular}{|c|c|c|c|}
\hline Site & $\begin{array}{c}\mathrm{L}_{\text {eq }} \text { of } 4 \mathrm{kHz} \text { noise } \\
\text { before pipe } \\
\text { sheathing, } \mathrm{dB}(\mathrm{A})\end{array}$ & $\begin{array}{c}\mathrm{L}_{\mathrm{eq}} \text { of } 4 \mathrm{kHz} \text { noise } \\
\text { after pipe } \\
\text { sheathing, } \mathrm{dB}(\mathrm{A})\end{array}$ & $\begin{array}{c}4 \mathrm{kHz} \text { noise } \\
\text { reduction } \mathrm{dB}(\mathrm{A})\end{array}$ \\
\hline Office 1 & 79 & 58 & 21 \\
\hline Office 2 & 94.7 & 77.7 & 17 \\
\hline
\end{tabular}

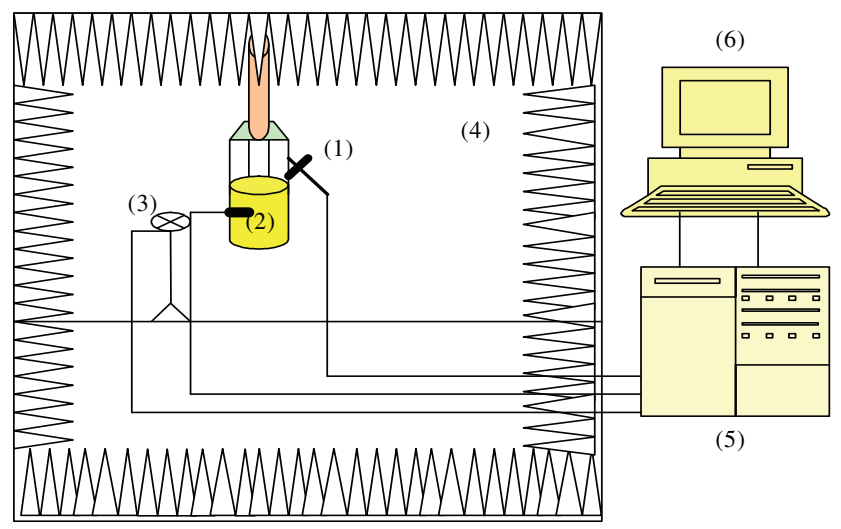

$\begin{array}{llll}\text { (1) hammer (2) accelerometer (3) microphone (4) anechoic chamber } & \end{array}$ (5) FFT (6) computer

Fig. 4. Experimental arrangement for EMA.

Table 2. Whereas, is there any way to make further improvement for the noise reduction in the offices? Intuitively, this can be envisaged by inserting an insulation layer in the pipe sheathing material. Basically, the countermeasure of noise insulation will enable the reduction of pipe noise more effective than the measure of noise absorption. Besides, the adhesive to bind the sheathing layers can also perform some damping behavior to the pipe wall vibrations.

\section{MOBILITY SPECTRUM OF PIPE SEGMENT BY EMA AND FEA}

Normally, pipe flow noise is generated by the fluctuation of pipe entrained fluid excited by sources in the fluid such as pumps and the vibration of pipe wall excited by mechanical connections to a vibrating machine. Thus, potentially many different types of wave could exist within a pipe structure and the entrained fluid. Aimed at the evaluation of the attenuation effectiveness of pipe sheathing on pipe flow noise, methodology should be established. The most important parameters governing the pipe noise radiation may be the vibration mode and mobility spectral function of pipe wall structure. Mode shape can influence radiation efficiency of pipe wall vibration and mobilily spectral function can be used to compare and assess the vibration attenuation in pipe wall with different sheathing materials.

The modal analysis and mobility spectral function of a pipe segment with or without sheathing material can be conducted by using the finite element analysis (FEA) and the experimental modal analysis (EMA) is employed to validate the correctness of the FEA model. Furthermore, in the application of FEA the contact elements should be used to represent the behavior of the adhesive layers in a sandwich sheathing material or the overlapping interface of two materials. For the adhesive layers, both modulus of elasticity and shear modulus will be attained as input data, while for the overlapping contact element only the friction coefficient is taken as an inpit. 

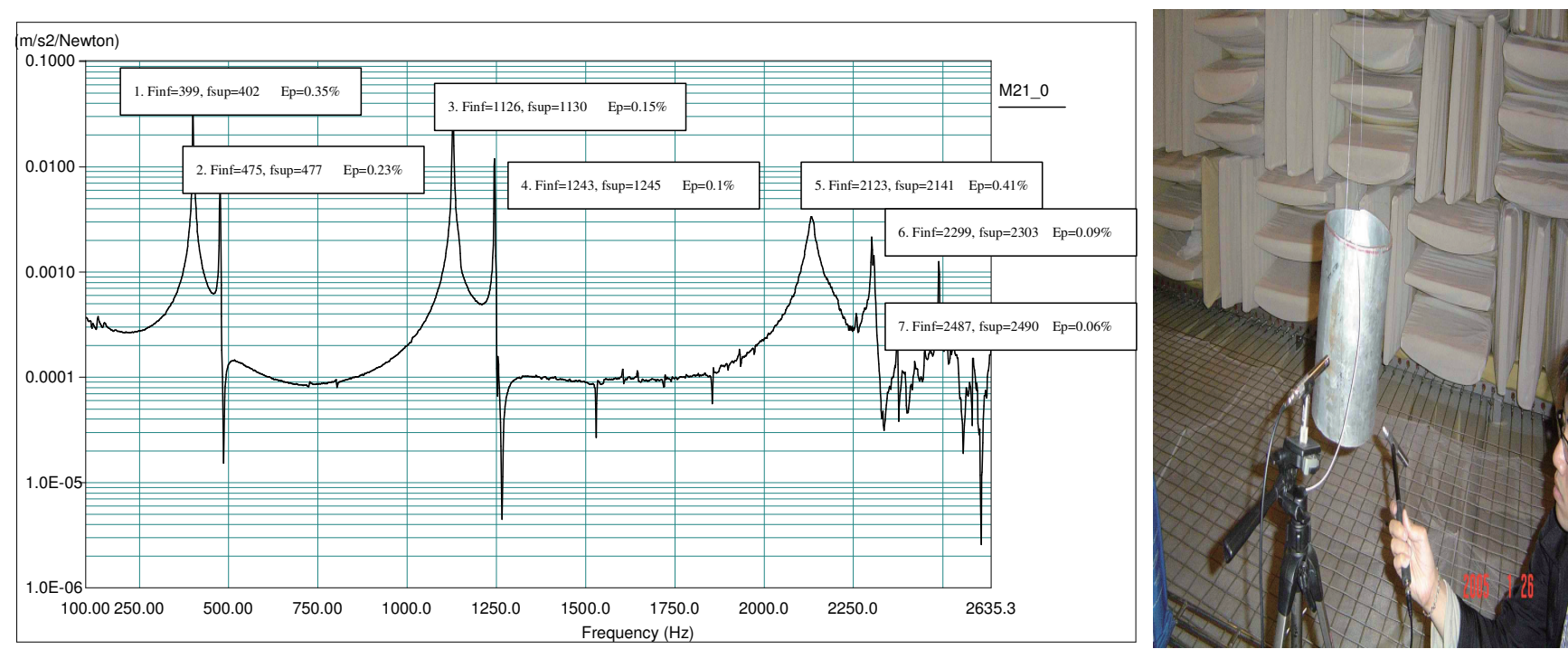

Fig. 5. Diving point mobility spectrum and modal damping obtained by EMA.

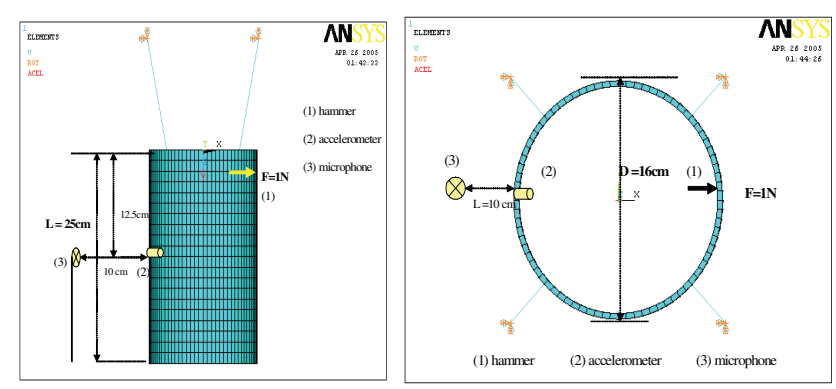

Fig. 6. Dimension and FE mesh of typical $16 \mathrm{~cm} \varphi$ bare pipe segment.

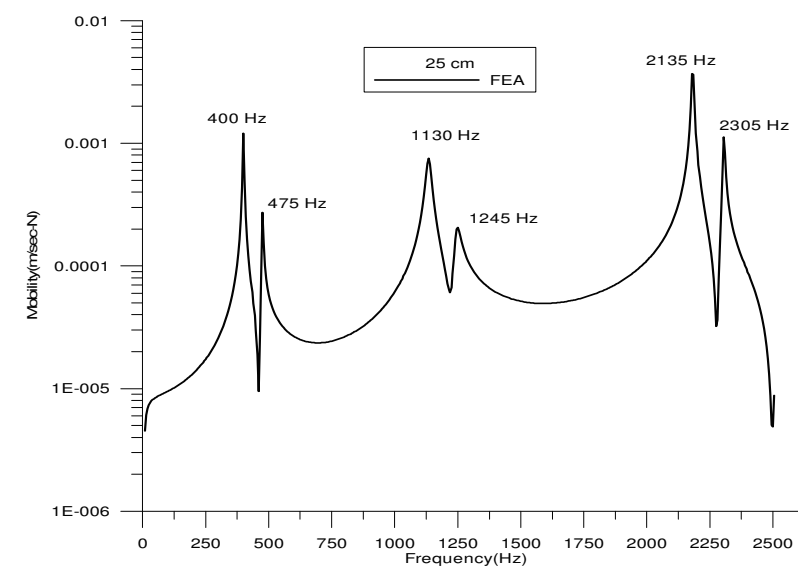

Fig. 7. Driving point mobility spectrum of a typical $16 \mathrm{~cm} \varphi$ bare pipe segment.

\section{Mobility Spectrum from EMA}

The EMA is carried and in an anechoic chamber with the use of an impact hammer as the actuator, and an accelerometer and a microphone as the sensors are used to obtain the frequency response functions, which encompass the driving point mobility spectral function and the driving force-to-sound pressure transfer function. Fig. 4 shows the arrangement of modal testing. The driving point is at the mid-length of the naked pipe wall. The driving point mobility spectrum by EMA and the modal damping obtained by the half power method and expressed in the Rayleigh damping form are shown in Fig. 5. In which, the half power frequencies at each resonant peak frequency are noted as $f_{\text {inf }}$ and $f_{\text {sup }}$ respectively. $E_{p}$ represents the modal damping ratio. These experimental modal damping data are then used for the input to the FEA.

\section{Vibration Mode and Mobility by FEA}

To perform the modal analysis and harmonic analysis for the pipe segment, the FEA software ANSYS 7.0 is used. The purpose of the modal analysis is to identify the pipe structural modal parameters which are the natural frequencies and the related mode shapes. The dimensions of the pipe seqment and the FE mesh for the modal and the harmonic mobility analyses are shown in Fig. 6. In which, 1600 type 45 solid elements are used to model a pipe of $25 \mathrm{~cm}$ long and $16 \mathrm{~cm}$ in diameter with wall thickness $4 \mathrm{~mm}$. In the analysis of harmonic mobility spectrum, a unit harmonic force is applied at a point on the wall of mid-length. Other material constants given in the analysis are the Young's moduls $\mathrm{E}=2.1 \mathrm{E} 11 \mathrm{~N} / \mathrm{m}^{2}$, Poisson's ratio $v=0.3$, and the density $\rho=7910 \mathrm{~kg} / \mathrm{m}^{3}$. Using the modal damping ratios shown in Fig. 5 by EMA, the driving point mobility spectrum is analyzed by FEA as shown in Fig. 7, in which six peaks ranged from $400 \mathrm{~Hz}$ to $2305 \mathrm{~Hz}$ can be seen. These six peak frequencies are refereed to as the natural frequencies. Accordingly, the related mode shapes are also analyzed and shown in Fig. 8. These modes, corresponding to the natural frequencies 400, 475, 1130, 1245, 2135 and $2305 \mathrm{~Hz}$ respectively, are more or less pertaining to the breathing modes or transverse bending modes of the pipe segment and can radiate high noise level as a consequence. 


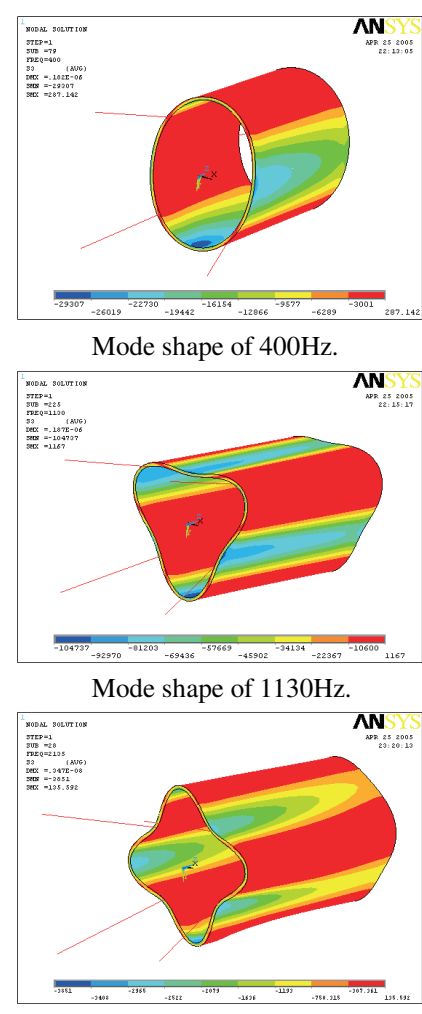

Mode shape of $2135 \mathrm{~Hz}$.

Fig. 8. Mode shapes of bare pipe segment in frequency range between 400 Hz to $2305 \mathrm{~Hz}$.

Table 3. Modal frequencies and mode shapes of bare pipe segment of different length.

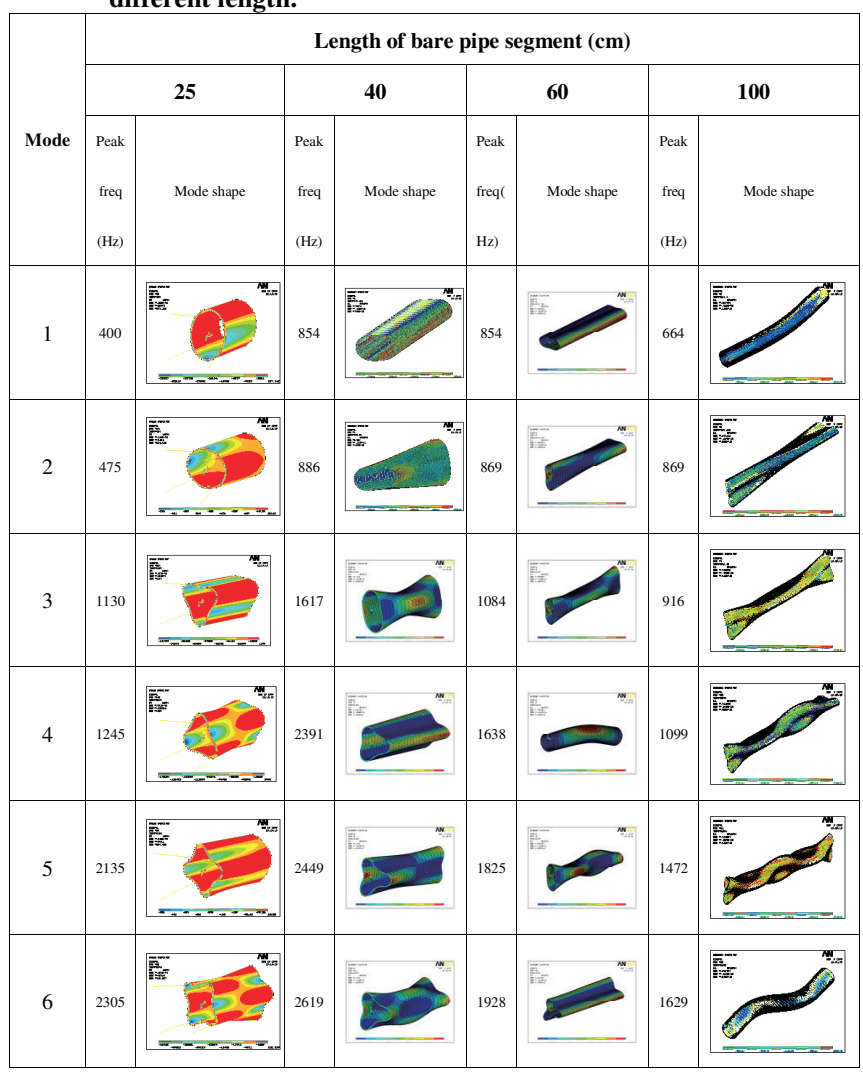

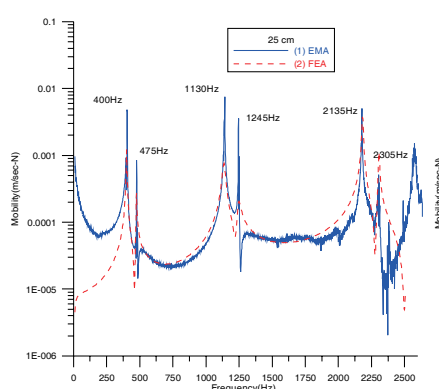

(a) Pipe length $25 \mathrm{~cm}$

(c) Pipe length $60 \mathrm{~cm}$

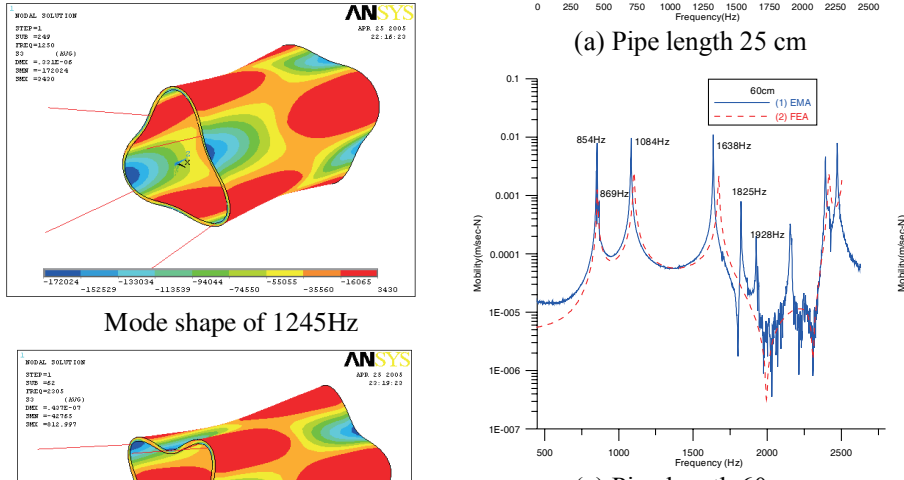

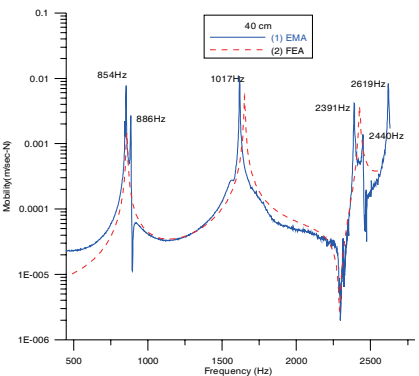

(b) Pipe length $40 \mathrm{~cm}$

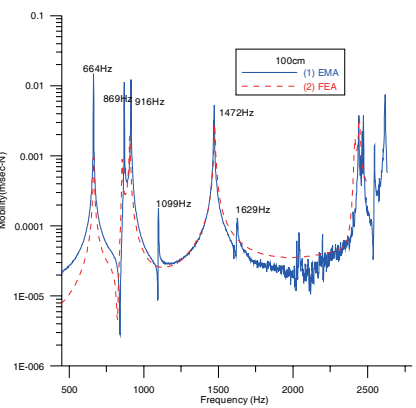

(d) Pipe length $100 \mathrm{~cm}$

Fig. 9. Comparison of mobility spectra by EMA and FEA for different bare pipe length.

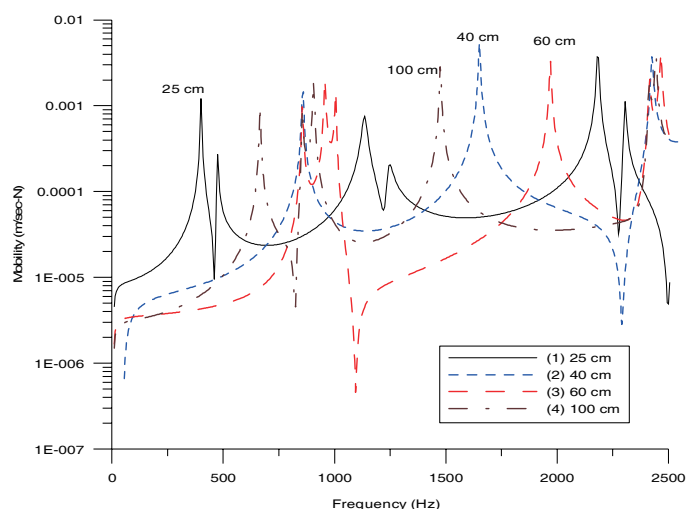

Fig. 10. Length effect on mobility spectra of bare pipe segments by FEA.

\section{Validation of Analysis Model and Length Effect}

The mobility spectra resulted by FEA solutions for a number of pipe segments, of different length $25 \mathrm{~cm}, 40 \mathrm{~cm}, 60 \mathrm{~cm}$, and $100 \mathrm{~cm}$ but same diameter respectively, are compared with that by EMA for the purpose of model validation. The comparisons of mobility spectra by EMA and FEA for different pipe length are shown in Fig. 9. From the good coincidence of these spectra, it is confident to use the current FE model further to simulate the radiation of pipe noise. In addition, the length effect on the mobility spectra by FEA of the bare pipe segment are compared as shown in Fig. 10, and the modal frequencies and mode shapes are compared in Table 3. There exhibits sensitive length effects on the modal parameters. Also, it can be seen the tendency that the pipe longitudinal bending modes are pertaining to lower modes for longer bare pipes, while the transverse bending 


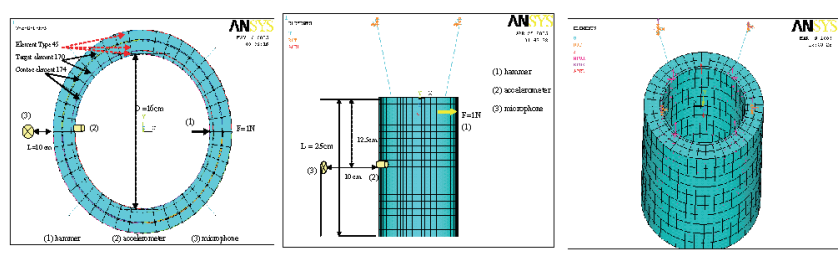

Fig. 11. FE mesh and elements used for modal analysis of pipe segment sheathed by sandwich material.

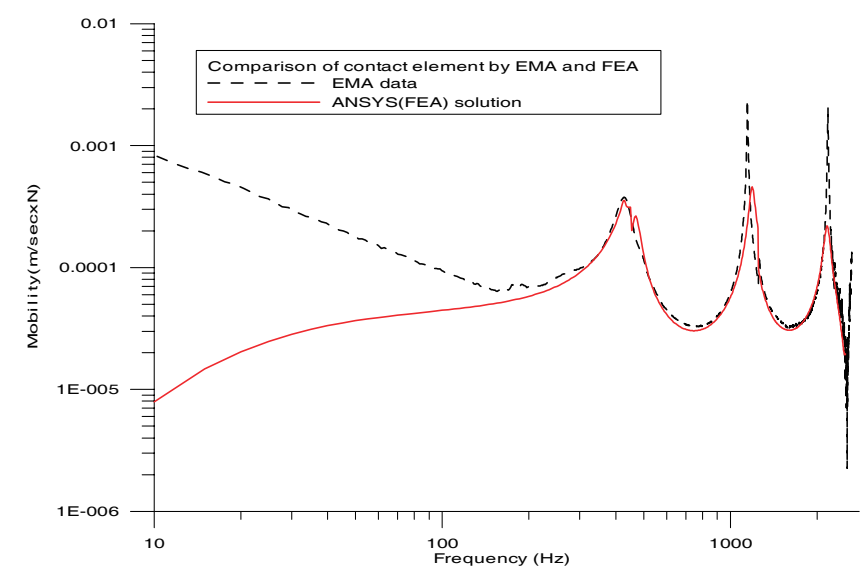

Fig. 12. Comparison of mobility spectra by EMA and FEA of sheathe pipe segment.

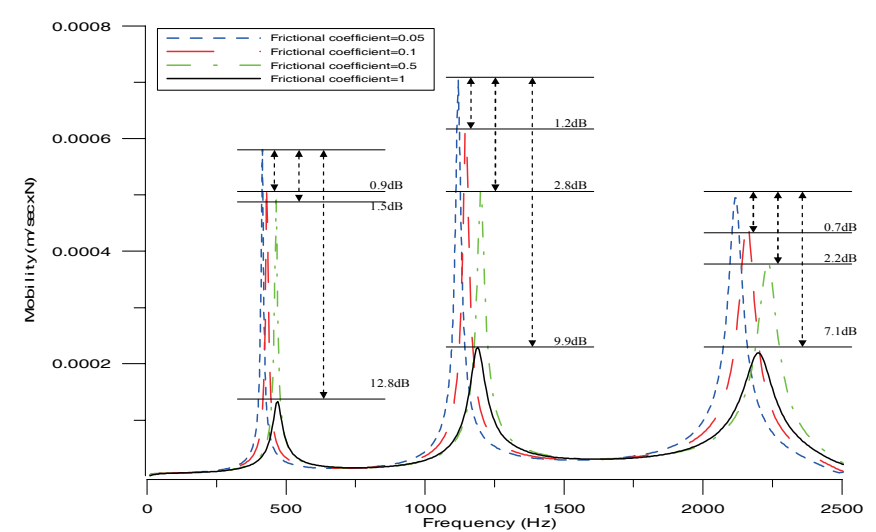

Fig. 13. Parametric analysis of frictional coefficient vibration on mobility spectrum.

modes pertaining to lower modes for shorter pipes.

\section{Application of Coupled FEA and EMA to Pipe Segment with Sandwich Sheathing Material}

Consider a galvanizing steel pipe segment, $25 \mathrm{~cm}$ long and $16 \mathrm{~cm}$ in diameter, sheathed by sandwich material, in which a layer of aluminum foil $+1 \mathrm{~cm}$ PE layert $1 \mathrm{~mm}$ lead sheet $+1 \mathrm{~cm}$ PE layer are composed. In FEA, each layer is modeled by solid elements with different Young's modulus, Poisson's ratio and density. While the interface between two layers is modeled by element type Target 170 for the outer side surface (or target surface) and element type Conta 174 for the inner side surface (or contact surface). Frictional coefficient $(\eta)$ between these two kinds elements should be input into the FEA model. Take $\eta=1.0$ for the case of tight contact between layers by adhesive bond. If

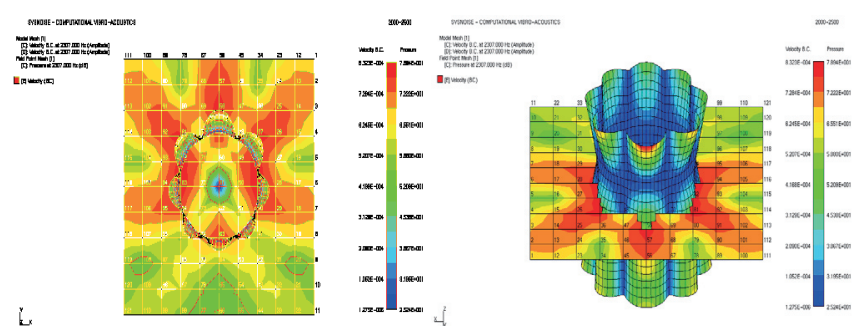

Fig. 14. BEM panel and FEA mesh in sound field analysis.

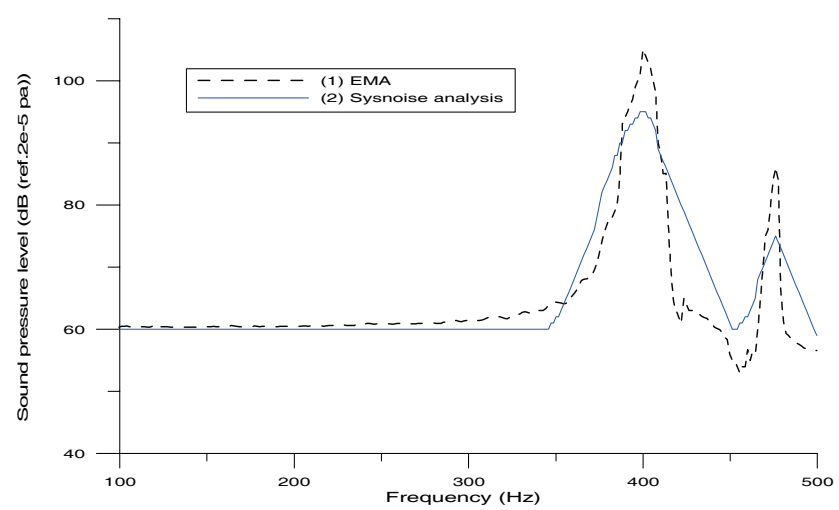

Fig. 15. Comparison of sound pressure level spectra by EMA and BEM at point $A$.

the contact of sheathing material with the pipe wall is intermittent by winding tape, then take $\eta<1.0$. The FEA mesh and the elements used for the modal and mobility spectral analyses is shown in Fig. 11. The mobility spectrum obtained by FEA is also compared with that by EMA, as Fig. 12, for this case as the pipe sheathed by sandwich material. The good coincidence validates the correctness of the FEA model. Consequently, a sensitivity analysis can be carried out by this FEA model to approach the effect of frictional coefficient on the mobility spectrum. Figure 13 shows the vibration of mobility spectra for the case of $\eta=0.05,0.5$ and 1.0. There appears a deduction of $1.5 \sim 12 \mathrm{~dB}$ in peak mobilities as the frictional coefficient increases 10 times. The damping ratio $\left(E_{P}\right)$ input to FEA is determined by EMA and the half power method as abovementioned. The frequency dependent Rayleigh damping coefficients $\alpha$ and $\beta$ adopted in the analyses are shown in Table 6 .

\section{RADIATED PIPE NOISE ANALYSIS BY BEM}

The radiated sound generated by pipe wall vibration was performed by the software package SYSNOISE. Basically SYSNOISE was coded by utilizing the boundary element method (BEM) capable of analyzing the fluid-borne sound pressure radiated from a set of structure-borne vibration sources. Thus, the interface data file for the pipe wall vibration analysis by FEA has to be compatible to the fluid-borne sound field model for BEM. In the study, an interface program has been developed to couple the softwares SYSNOISE and ANSYS. The interface panels model for SYSNOISE and the elements mesh for FEA of a pipe segment are shown in Fig. 14. The sound pressure level at a field point $\mathrm{A}, 10 \mathrm{~cm}$ apart from the pipe wall 


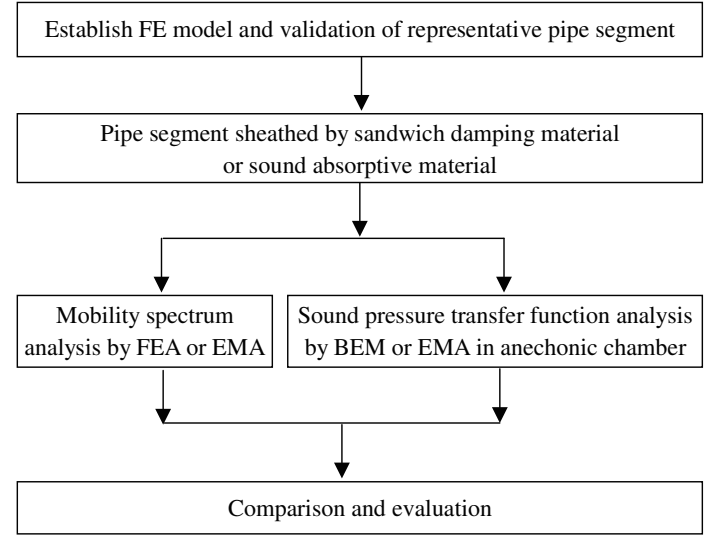

Fig. 16. Evaluation scheme for quantification of sound isolation of pipe sheathing material.

Table 4. Composition of pipe sheathing materials.

\begin{tabular}{|c|l|l|}
\hline Type No. & \multicolumn{1}{|c|}{ Category } & \multicolumn{1}{|c|}{ Composition of pipe sheathing } \\
\hline 0 & Naked pipe & galvanizing steel pipe (GSP) \\
\hline 1 & Sound absorptive & 1 1" PU layer + GSP \\
\hline 2 & Sound absorptive & 1" Glass wool (GW) layer $+\mathrm{GSP}$ \\
\hline 3 & Sound absorptive & Plastic membrane +1 " GW layer + GSP \\
\hline 4 & Damping & 1mm Iron powder included rubber layer $+\mathrm{GSP}$ \\
\hline 5 & Sandwich damping & $\begin{array}{l}\text { Aluminum foil }+1 \mathrm{~cm} 32 \mathrm{~K} \text { GW layer }+1 \mathrm{~mm} \text { lead sheet }+1 \mathrm{~cm} \\
32 \mathrm{~K} \text { GW layer }+\mathrm{GSP}\end{array}$ \\
\hline 6 & Sandwich damping & $\begin{array}{l}\text { Aluminum foil }+1 \mathrm{~cm} \text { PE layer }+1 \mathrm{~mm} \text { lead sheet }+1 \mathrm{~cm} \mathrm{PE} \\
\text { layer }+\mathrm{GSP}\end{array}$ \\
\hline
\end{tabular}

in the mid-plane of the pipe, generated by unit harmonic impulsive forces with the frequency band from $1 \sim 500 \mathrm{~Hz}$ is analyzed. The result of analyzed radiated pipe sound spectrum has compared with that obtained by measurement as shown in Fig. 15. The coincidence is fair good.

\section{COMPARATIVE STUDY OF NOISE ATTENATION BY PIPE SHEATHING}

Usually, pipe flow noise can be attenuated by the use of sheathing material on pipe wall. While there are a number of materials can be selected. To quantify the isolation effectiveness of such materials on pipe flow noise, the evaluation scheme, as shown in Fig. 16, is developed. In which the experimental arrangement for FMA is the same as shown in Fig. 4.

For comparative study, six types sheathing material are selected. Three of which are characterized as sound absorptive
Table 5. Equivalent Rayleigh damping coefficients of 6 type pipe sheath.

\begin{tabular}{|c|c|c|c|c|c|c|}
\hline \multirow{2}{*}{$\begin{array}{c}\text { Sheathing } \\
\text { type }\end{array}$} & \multicolumn{2}{|c|}{ Frequency band } & \multicolumn{2}{|c|}{ Modal damping ratio } & \multicolumn{2}{|c|}{$\begin{array}{l}\text { Rayleigh damping } \\
\text { coefficients }\end{array}$} \\
\hline & $\begin{array}{c}\mathbf{f}_{\text {inf }} \\
(\mathbf{H z})\end{array}$ & $\begin{array}{l}\mathbf{f}_{\text {sup }} \\
(\mathrm{Hz})\end{array}$ & at $f_{\text {inf }}$ & at $\mathrm{f}_{\text {sup }}$ & $\alpha$ & $\boldsymbol{\beta}$ \\
\hline \multirow{4}{*}{$\mathbf{0}$} & 400 & 476 & 0.0035 & 0.0023 & 168.45 & $-2.32 \mathrm{E}-07$ \\
\hline & 476 & 1128 & 0.0023 & 0.0015 & 76.23 & $2.89 \mathrm{E}-08$ \\
\hline & 1128 & 1244 & 0.0015 & 0.0010 & 297.17 & $-8.24 \mathrm{E}-08$ \\
\hline & 1244 & 2132 & 0.0010 & 0.0041 & -207.35 & $1.27 \mathrm{E}-07$ \\
\hline \multirow{3}{*}{1} & 394 & 1111 & 0.0040 & 0.0056 & 71.67 & $2.18 \mathrm{E}-07$ \\
\hline & 1111 & 2107 & 0.0056 & 0.0137 & -197.31 & $3.58 \mathrm{E}-07$ \\
\hline & 2107 & 2357 & 0.0137 & 0.0260 & -7902.41 & $1.47 \mathrm{E}-06$ \\
\hline \multirow{3}{*}{2} & 401 & 1127 & 0.0033 & 0.0020 & 93.83 & $4.25 \mathrm{E}-08$ \\
\hline & 1127 & 2143 & 0.0020 & 0.0019 & 123.10 & $2.77 \mathrm{E}-08$ \\
\hline & 2143 & 2500 & 0.0019 & 0.0024 & -100.35 & $5.89 \mathrm{E}-08$ \\
\hline \multirow{5}{*}{3} & 401 & 474 & 0.0068 & 0.0055 & 239.11 & $-9.50 \mathrm{E}-08$ \\
\hline & 474 & 1128 & 0.0055 & 0.0024 & 204.14 & $4.84 \mathrm{E}-09$ \\
\hline & 1128 & 1244 & 0.0024 & 0.0023 & 157.52 & $2.83 \mathrm{E}-08$ \\
\hline & 1244 & 2135 & 0.0024 & 0.0021 & 160.07 & $2.73 \mathrm{E}-08$ \\
\hline & 2135 & 2303 & 0.0021 & 0.0011 & 1295.39 & $-1.32 \mathrm{E}-07$ \\
\hline \multirow{3}{*}{4} & 384 & 457 & 0.0040 & 0.0037 & 91.90 & $1.28 \mathrm{E}-07$ \\
\hline & 457 & 1079 & 0.0037 & 0.0074 & 24.88 & $3.34 \mathrm{E}-07$ \\
\hline & 1079 & 2025 & 0.0074 & 0.0167 & -160.97 & $4.36 \mathrm{E}-07$ \\
\hline \multirow[t]{2}{*}{5} & 418 & 1131 & 0.0545 & 0.0046 & 2018.29 & $-8.06 \mathrm{E}-07$ \\
\hline & 1131 & 2080 & 0.0046 & 0.0059 & 176.47 & $1.17 \mathrm{E}-07$ \\
\hline
\end{tabular}

type and the other three are sandwich damping type. Their composition and structure are described in Table 4.

Similar procedures based on EMA are applied to determine the loss factors of the pipe segment sheathed by the six types of sandwich materials. The results of measured loss factors are shown in Fig. 17, and the analyzed equivalent Rayleigh damping coefficients are summarized in Table 5.

By the scheme in Fig. 16, these six sheathing samples have been evaluated. Comparisons of the measured mobility spectral functions and sound pressure transfer functions are shown as Figs. 18 and 19 respectively. From which, the reductions of mobility function and the radiated sound pressure at peak frequencies by the six types sheathing material are summarized in Tables 6 and 7 and Figs. 20 and 21. From Figs. 20 and 21 it can be seen that three types damping material sheathing appear better performance both in the reduction of mobility and radiated sound pressure transfer.

\section{SUMMARY AND CONSLUSIONS}

An evaluation methodology based on FEM, EMA and BEM to assess the vibroacoustic attenuation effect of sandwich damping material on pipe flow noise has been established and discussed. From the comparative study of six types selected sheathing 


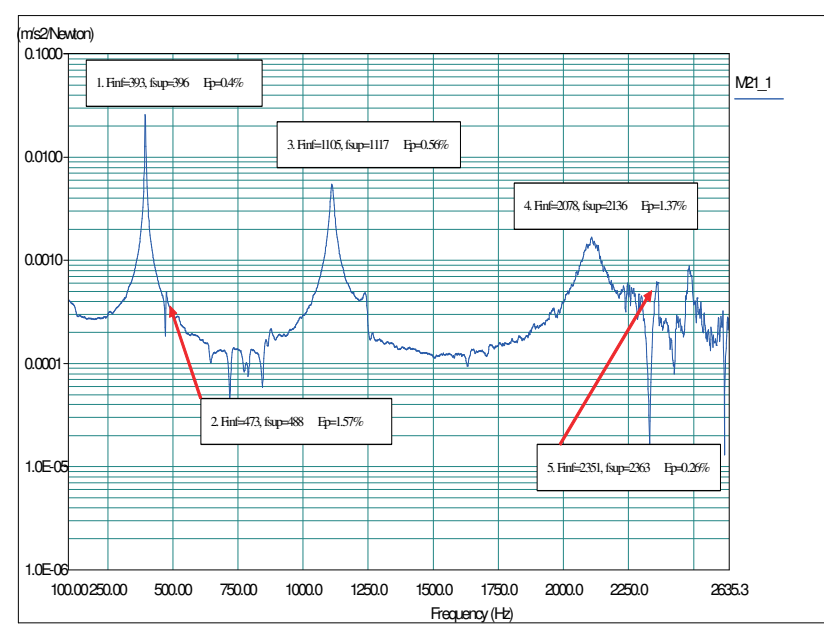

(a) Type 1 sheathing

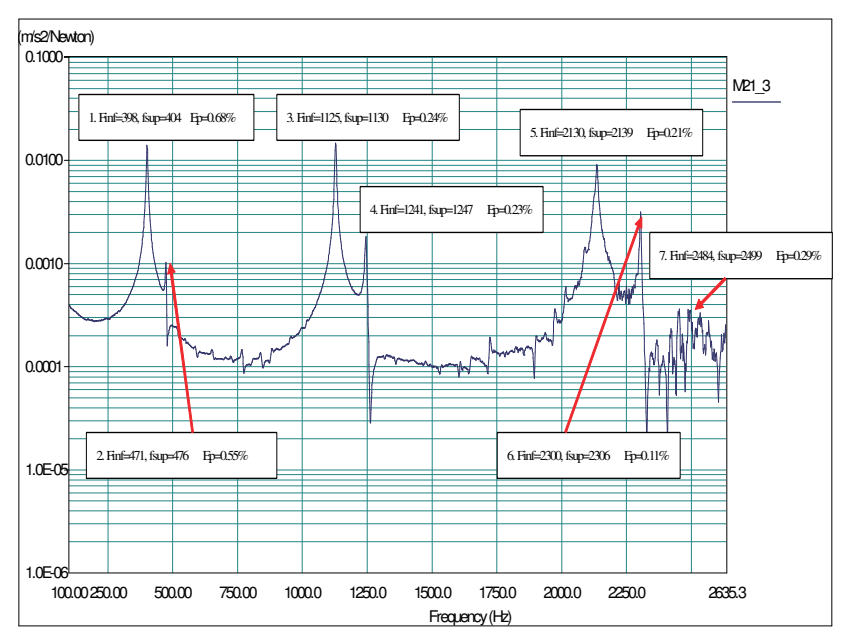

(c) Type 3 sheathing

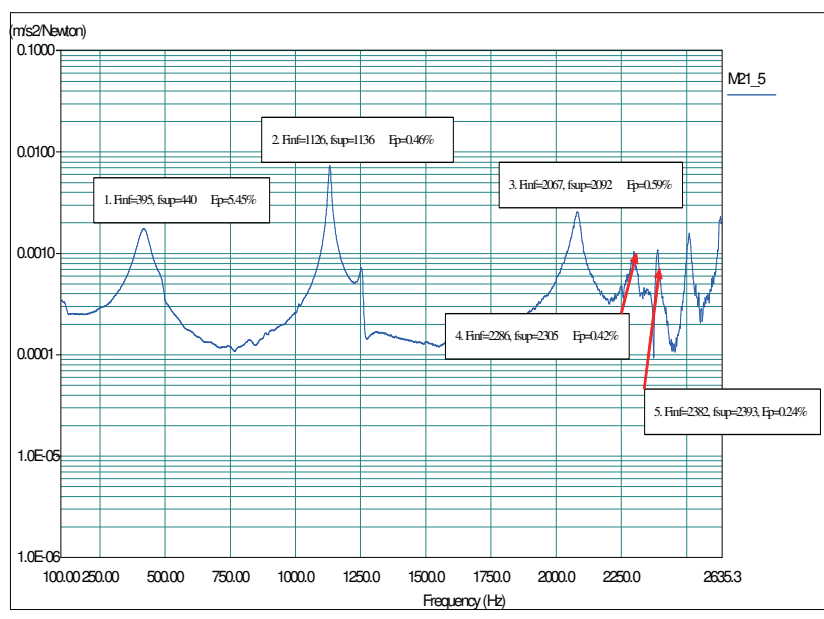

(e) Type 5 sheathing

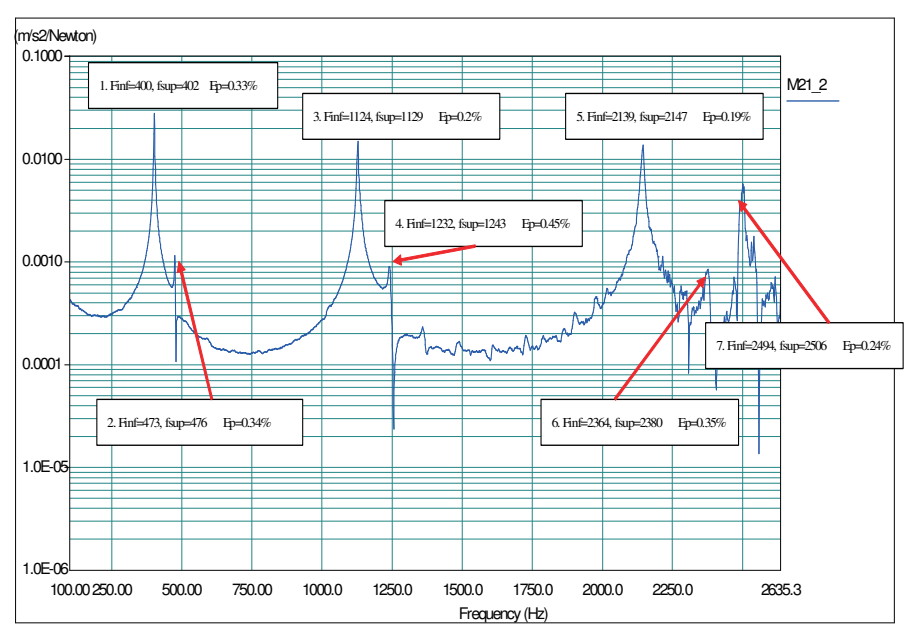

(b) Type 2 sheathing

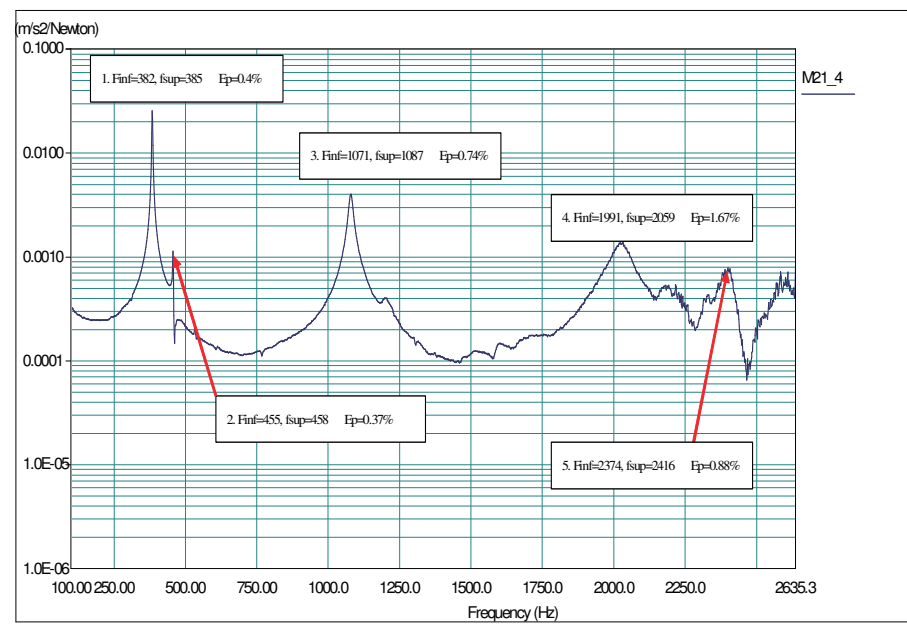

(d) Type 4 sheathing

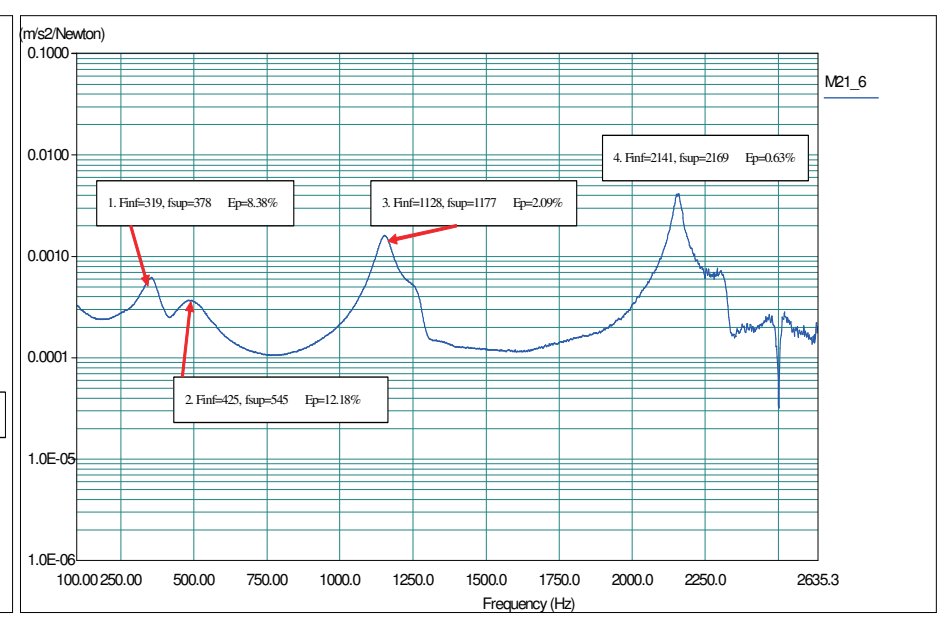

(f) Type 6 sheathing materials by use of the evaluation sheme, it has shown that the sandwich damping materials can further reduce the radiated pipe flow noise by an amount of $12-15 \mathrm{~dB}$ than that of pure sound absorptive sheathing materials.
VII. ACKNOWLEDGMENTS

Sponsorship from the National Science Council of the Republic of China for the project NSC-96-2221-E-019-055 is appreciated. 


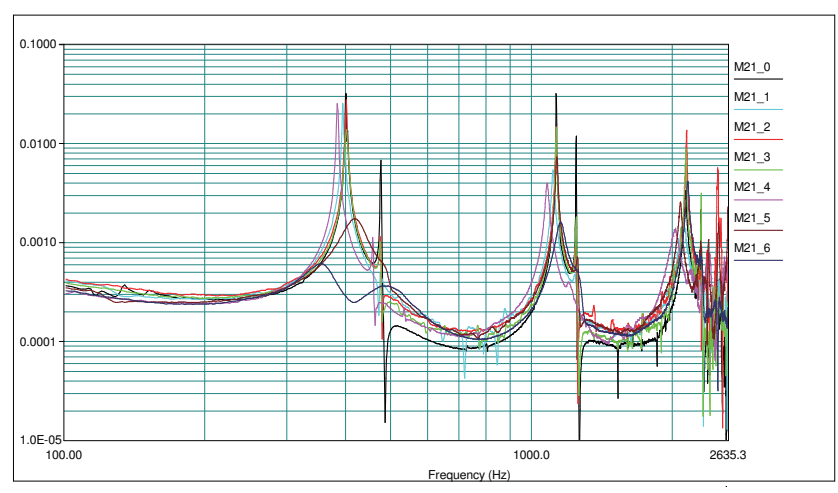

Fig. 18. Comparison of mobility spectral function by EMA related to different pipe sheathing material.

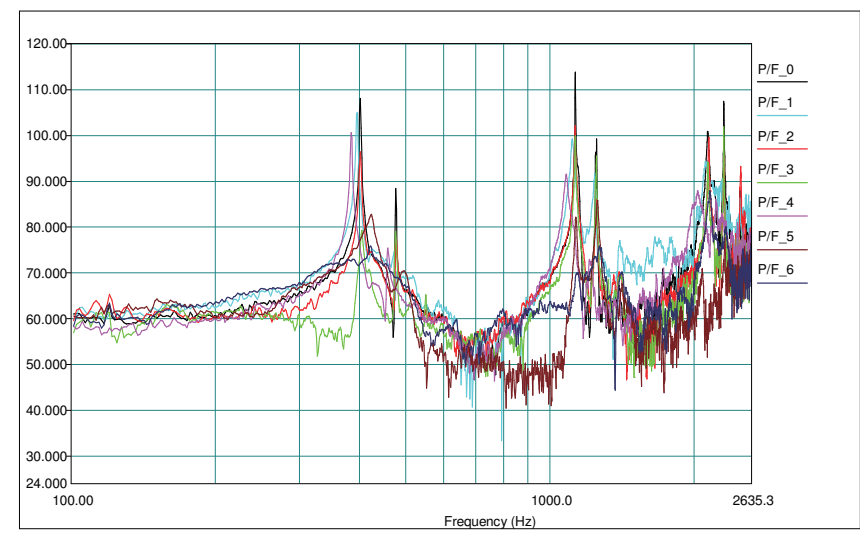

Fig. 19. Comparison of sound pressure transfer function by EMA related to different pipe sheathing material.

Table 6. Reduction of mobility function at peak fvequcies.

\begin{tabular}{|c|c|c|c|c|c|c|c|c|c|c|c|c|}
\hline \multirow{3}{*}{$\begin{array}{c}\begin{array}{c}\text { Mobility } \\
\text { and } \\
\text { reduction }\end{array} \\
\begin{array}{c}\text { Sheathing } \\
\text { material }\end{array}\end{array}$} & \multicolumn{12}{|c|}{ Peak frequency $(\mathrm{Hz})$} \\
\hline & \multicolumn{2}{|c|}{401} & \multicolumn{2}{|c|}{476} & \multicolumn{2}{|c|}{1130} & \multicolumn{2}{|c|}{1250} & \multicolumn{2}{|c|}{2132} & \multicolumn{2}{|c|}{2307} \\
\hline & \begin{tabular}{|c} 
Mobility \\
$\left(10^{3} \mathrm{~m} / \mathrm{s} / \mathrm{N}\right)$
\end{tabular} & \begin{tabular}{|c|c}
$\begin{array}{c}\text { Reduction } \\
(\mathrm{dB})\end{array}$ \\
\end{tabular} & \begin{tabular}{|c|c|}
$\begin{array}{c}\text { Mobility } \\
\left(10^{\circ} \text { mils }\right.\end{array}$ \\
\end{tabular} & \begin{tabular}{|c|c|}
$\begin{array}{c}\text { Recuction } \\
(\mathrm{dB})\end{array}$ \\
\end{tabular} & \begin{tabular}{|c|c|}
$\begin{array}{c}\text { Mobility } \\
\left(10^{3} \mathrm{~m} u s-\mathrm{N}\right)\end{array}$ \\
\end{tabular} & \begin{tabular}{|c}
$\begin{array}{c}\text { Reduction } \\
(\mathrm{dBB})\end{array}$ \\
\end{tabular} & \begin{tabular}{|c|}
$\begin{array}{c}\text { Mobility } \\
\left(10^{3} \mathrm{~ms}-\mathrm{N}\right)\end{array}$ \\
\end{tabular} & \begin{tabular}{|c} 
Reduction \\
$(\mathrm{AB})$
\end{tabular} & \begin{tabular}{|c|c|}
$\begin{array}{c}\text { Mobiliti } \\
\left(10^{\circ} \mathrm{m} / \mathrm{N} / \mathrm{N}\right)\end{array}$ \\
\end{tabular} & \begin{tabular}{|c|c}
$\begin{array}{c}\text { Reduction } \\
(\mathrm{AB})\end{array}$ \\
\end{tabular} & \begin{tabular}{|c|}
$\begin{array}{c}\text { Mobility } \\
\left(10^{\prime} \mathrm{m} / \mathrm{s} / \mathrm{N}\right)\end{array}$ \\
\end{tabular} & \begin{tabular}{|c|c|}
$\begin{array}{c}\text { Reduction } \\
(\mathrm{AB})\end{array}$ \\
\end{tabular} \\
\hline Type 0 & 31.66 & 0 & 6.77 & 0 & 15.66 & 0 & 11.84 & 0 & 3.34 & 0 & 1.43 & 0 \\
\hline Type 1 & 5.11 & 15.8 & 0.48 & 23.0 & 1.67 & 19.4 & 0.36 & 30.3 & 1.27 & 8.4 & 0.26 & 14.8 \\
\hline Type 2 & 27.67 & 1.2 & 0.97 & 16.9 & 7.31 & 6.62 & 0.53 & 27.0 & 5.82 & -4.8 & 0.08 & 25.0 \\
\hline Type 3 & 13.80 & 7.2 & 0.78 & 18.8 & 10.35 & 3.6 & 1.81 & 16.3 & 7.91 & -7.5 & 1.41 & 0.1 \\
\hline Type 4 & 1.61 & 25.9 & 0.25 & 28.7 & 0.67 & 27.4 & 0.24 & 33.9 & 0.42 & 18.0 & 0.28 & 14.2 \\
\hline Type 5 & 1.41 & 27.0 & 0.65 & 20.4 & 7.33 & 6.7 & 0.60 & 25.9 & 0.62 & 14.6 & 0.74 & 5.7 \\
\hline Type 6 & 0.3 & 40.5 & 0.36 & 25.5 & 11.78 & 2.5 & 0.53 & 27.0 & 0.21 & 24.0 & 0.66 & 6.7 \\
\hline
\end{tabular}

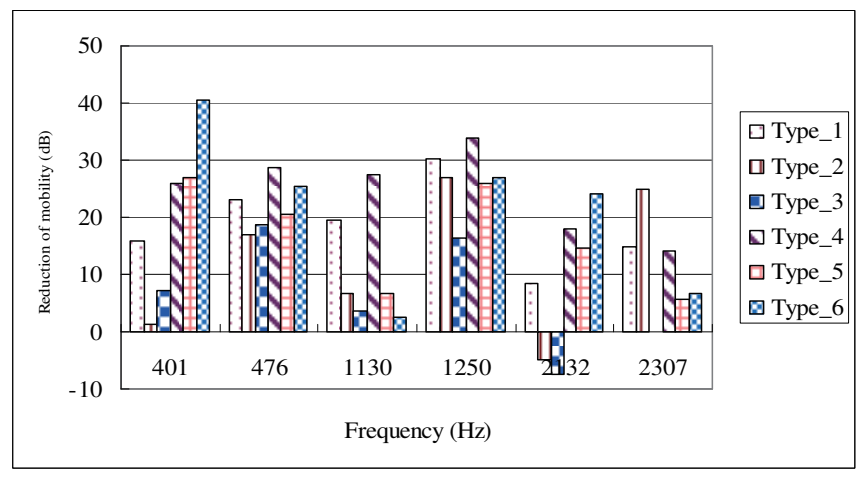

Fig. 20. Comparison of mobility reduction amongst different pipe sheathings at peak frequencies.
Table 7. Reduction of sound pressure transfer function at peak frequencies.

\begin{tabular}{|c|c|c|c|c|c|c|c|c|c|c|c|c|}
\hline \multirow{3}{*}{$\begin{array}{c}\text { Sound } \\
\text { pressure } \\
\text { transfer } \\
\text { function } \\
\text { and } \\
\text { reduction } \\
\begin{array}{l}\text { Sheathing } \\
\text { material }\end{array}\end{array}$} & \multicolumn{12}{|c|}{ Peak frequency $(\mathrm{Hz})$} \\
\hline & \multicolumn{2}{|c|}{401} & \multicolumn{2}{|c|}{476} & \multicolumn{2}{|c|}{1130} & \multicolumn{2}{|c|}{1250} & \multicolumn{2}{|c|}{2132} & \multicolumn{2}{|c|}{2307} \\
\hline & 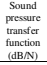 & $\begin{array}{l}\text { Reduction } \\
(\mathrm{dBR})\end{array}$ & 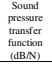 & 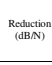 & 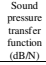 & $\begin{array}{l}\begin{array}{c}\text { Reduction } \\
(\mathrm{dB} / \mathrm{N})\end{array}\end{array}$ & 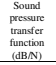 & $\begin{array}{l}\text { Reduction } \\
(\mathrm{dBR})\end{array}$ & 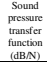 & $\begin{array}{l}\begin{array}{r}\text { Reduction } \\
(\mathrm{dBRN})\end{array}\end{array}$ & 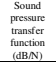 & $\begin{array}{c}\text { Reduction } \\
(\mathbb{d B} N) \text { (1) }\end{array}$ \\
\hline Type 0 & 108.0 & 0 & 88.4 & 0 & 105.6 & 0 & 96.2 & 0 & 100.8 & 0 & 105.7 & 0 \\
\hline Type 1 & 86.9 & 21.1 & 66.8 & 21.1 & 90.0 & 15.6 & 87.5 & 8.8 & 93.5 & 7.3 & 85.2 & 20.5 \\
\hline Type 2 & 96.3 & 11.7 & 75.8 & 12.6 & 95.8 & 9.8 & 79.9 & 16.3 & 91.1 & 9.7 & 94.2 & 11.5 \\
\hline Type 3 & 75.4 & 32.6 & 78.9 & 9.5 & 96.3 & 9.3 & 90.6 & 5.6 & 92.9 & 7.9 & 93.9 & 11.8 \\
\hline Type 4 & 74.9 & 33.1 & 66.5 & 21.9 & 75.7 & 29.8 & 62.1 & 34.1 & 76.8 & 24.0 & 81.0 & 24.7 \\
\hline Type 5 & 77.2 & 30.8 & 66.8 & 21.6 & 82.1 & 23.5 & 80.3 & 15.9 & 87.6 & 43.2 & 72.5 & 33.2 \\
\hline Type 6 & 72.0 & 36.0 & 68.9 & 19.5 & 69.4 & 36.2 & 73.6 & 22.7 & 84.4 & 16.4 & 76.7 & 29.0 \\
\hline
\end{tabular}

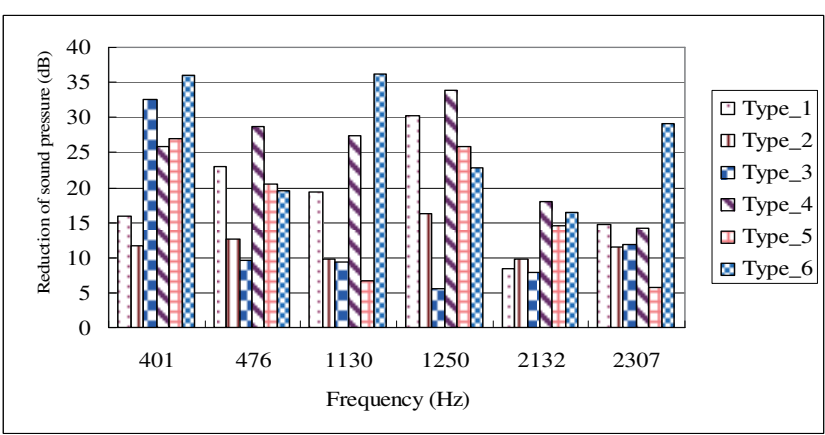

Fig. 21. Comparison of sound pressure reduction amongst different pipe sheathings at peak frequencies.

\section{REFERENCES}

1. Bull, M. K. and Norton, M. P., "On the hydrodynamic and acoustic wall presure fluctuations in turbulent pipe flow due to a $90^{\circ}$ mitred bend," Journal of Sound and Vibration, Vol. 69, No. 1, pp.1-11 (1981).

2. Dobson, B. J., Pinnigton, R. J., and White, R. G., Vibrational Power Transmission Analysis of Machinery Installations in Ships with the Objective of Noise Reduction, ISVR Technical Report, No. 216 (1993).

3. Fagerlund, A. C. and Chou, D. C., "Sound transmission through a cylindrical pipe wall," Journal of Engineering for Industry, (ASME Transactions), Vol. 103, pp. 355-360 (1981).

4. Holmer, C. I. and Heymann, F. J., "Transmission of sound through pipe walls in the presence of flow," Journal of Sound and Vibration, Vol. 70 No. 2, pp. 275-301 (1980).

5. Howard, I. M., Norton, M. P., and Stone, B. J., "A coincidence damper for reducing pipe wall vibration in piping systems with disturbed internal turbulent flow," Journal of Sound and Vibration, Vol. 113, No. 2, pp. 377-393 (1987)

6. Masti, R. S. and Sainsbury, M. G., "A study on the partial coating of a shell with an add-on viscoelastic layer for optimal damping design," Proceedings of International Symposium on Musical Acoustics, Leuven-Belgium, September, pp. 20-22 (2004).

7. Muggleton, J. M., Brennan, M. J., and Linford, P. W., "Axisymmetric wave propagation in fluid-filled pipes: wavenumber measurements in vacuo and buried pipes," Journal of Sound and Vibration, Vol. 270, pp. 171-190 (2004)

8. Norton, M. P. and Bull, M. K., "Mechanisms of the generation of external acoustic radiation form pipes due to internal flow disturbances," Journal of Sound and Vibration, Vol. 94, No. 1, pp. 105-146 (1984).

9. Pavić, G., "Acoustic analysis of pipes with flow using invariant field functions," Journal of Sound and Vibration, Vol. 263, pp. 153-174 (2003).

10. Li, P., Su, S. and Zuo, J., "A method of measuring the axial elastic modulus of a sandwich cylinder based on modal testing," Proceeding of the 14th International Congress on Sound \& Vibration, ICSV 14, Cairns-Australia, 9-12 July (2007). 